\title{
Convergence Results for a Common Solution of a Finite Family of Equilibrium Problems and Quasi-Bregman Nonexpansive Mappings in Banach Space
}

\author{
G. C. Ugwunnadi ${ }^{1}$ and Bashir Ali ${ }^{2}$ \\ ${ }^{1}$ Department of Mathematics, Michael Okpara University of Agriculture, Umudike, Abia State, Nigeria \\ ${ }^{2}$ Department of Mathematical Sciences, Bayero University Kano, PMB 3011, Kano, Nigeria
}

Correspondence should be addressed to G. C. Ugwunnadi; ugwunnadi4u@yahoo.com

Received 16 November 2015; Accepted 21 February 2016

Academic Editor: Mitsuru Sugimoto

Copyright (C) 2016 G. C. Ugwunnadi and B. Ali. This is an open access article distributed under the Creative Commons Attribution License, which permits unrestricted use, distribution, and reproduction in any medium, provided the original work is properly cited.

We introduce an iterative process for finding common fixed point of finite family of quasi-Bregman nonexpansive mappings which is a unique solution of some equilibrium problem.

\section{Introduction}

Let $E$ be a real reflexive Banach space and $C$ a nonempty subset of $E$. Let $T: C \rightarrow C$ be a map, a point $x \in C$ is called a fixed point of $T$ if $T x=x$, and the set of all fixed points of $T$ is denoted by $F(T)$. The mapping $T$ is called $L$ Lipschitzian or simply Lipschitz if there exists $L>0$, such that $\|T x-T y\| \leq L\|x-y\|, \forall x, y \in C$, and if $L=1$, then the map $T$ is called nonexpansive.

Let $g: C \times C \rightarrow \mathbb{R}$ be a bifunction. The equilibrium problem with respect to $g$ is to find

$$
z \in C \text { such that } g(z, y) \geq 0, \quad \forall y \in C .
$$

The set of solutions of equilibrium problem is denoted by $\mathrm{EP}(g)$. Thus

$$
\mathrm{EP}(g):=\{z \in C: g(z, y) \geq 0, \forall y \in C\} .
$$

Numerous problems in physics, optimization, and economics reduce to finding a solution of the equilibrium problem. Some methods have been proposed to solve equilibrium problem in Hilbert spaces; see, for example, Blum and Oettli [1], Combettes and Hirstoaga [2]. Recently, Tada and Takahashi $[3,4]$ and S. Takahashi and W. Takahashi [5] obtain weak and strong convergence theorems for finding a common element of the set of solutions of an equilibrium problem and set of fixed points of nonexpansive mapping in Hilbert space. In particular, Takahashi and Zembayashi [4] establish a strong convergence theorem for finding a common element of the two sets by using the hybrid method introduced in Nakajo and Takahashi [6]. They also proved such a strong convergence theorem in a uniformly convex and uniformly smooth Banach space.

In 1967, Bregman [7] discovered an elegant and effective technique for using so-called Bregman distance function $D_{f}$; see (3) in the process of designing and analyzing feasibility and optimization algorithms. This opened a growing area of research in which Bregman's technique has been applied in various ways in order to design and analyze iterative algorithms for solving feasibility and optimization problems.

Let $f: E \rightarrow(-\infty,+\infty]$ be a convex and Gâteaux differentiable function. The function $D_{f}: \operatorname{dom} f \times \operatorname{int} \operatorname{dom} f \rightarrow$ $[0,+\infty)$ defined as

$$
D_{f}(y, x):=f(y)-f(x)-\langle\nabla f(x), y-x\rangle
$$

is called the Bregman distance with respect to $f$ (see [8]). It is obvious from the definition of $D_{f}$ that

$$
\begin{aligned}
D_{f}(z, x)= & D_{f}(z, y)+D_{f}(y, x) \\
& +\langle\nabla f(y)-\nabla f(x), z-y\rangle .
\end{aligned}
$$


We observed from (4) that, for any $y_{1}, y_{2}, \ldots, y_{N} \in E$, the following holds:

$$
\begin{aligned}
D_{f}\left(y_{1}, y_{N}\right) & \\
= & \sum_{k=2}^{N} D_{f}\left(y_{k-1}, y_{k}\right) \\
& +\sum_{k=3}^{N}\left\langle\nabla f\left(y_{k-1}\right)-\nabla f\left(y_{k}\right), y_{k-1}-y_{1}\right\rangle .
\end{aligned}
$$

Recall that the Bregman projection [7] of $x \in \operatorname{int} \operatorname{dom} f$ onto the nonempty closed and convex set $C \subset \operatorname{dom} f$ is the necessarily unique vector $P_{C}^{f}(x) \in C$ satisfying

$$
D_{f}\left(P_{C}^{f}(x), x\right)=\inf \left\{D_{f}(y, x): y \in C\right\} .
$$

A mapping $T$ is said to be Bregman firmly nonexpansive [9], if, for all $x, y \in C$,

$$
\begin{aligned}
& \langle\nabla f(T x)-\nabla f(T y), T x-T y\rangle \\
& \quad \leq\langle\nabla f(x)-\nabla f(y), T x-T y\rangle,
\end{aligned}
$$

or, equivalently,

$$
\begin{aligned}
& D_{f}(T x, T y)+D_{f}(T y, T x)+D_{f}(T x, x)+D_{f}(T y, y) \\
& \quad \leq D_{f}(T x, y)+D_{f}(T y, x) .
\end{aligned}
$$

A point $p \in C$ is said to be asymptotic fixed point of a map $T$, if, for any sequence $\left\{x_{n}\right\}$ in $C$ which converges weakly to $p, \lim _{n \rightarrow \infty}\left\|x_{n}-T x_{n}\right\|=0$. We denote by $\widehat{F}(T)$ the set of asymptotic fixed points of $T$. Let $f: E \rightarrow \mathbb{R}$; a mapping $T: C \rightarrow C$ is said to be Bregman relatively nonexpansive [10] if $F(T) \neq \emptyset, \widehat{F}(T)=F(T)$, and $D_{f}(p, T(x)) \leq D_{f}(p, x)$ for all $x \in C$ and $p \in F(T)$. T is said to be quasi-Bregman relatively nonexpansive if $F(T) \neq \emptyset$, and $D_{f}(p, T(x)) \leq D_{f}(p, x)$ for all $x \in C$ and $p \in F(T)$.

Recently, by using the Bregman projection, in 2011 Reich and Sabach [9] proposed algorithms for finding common fixed points of finitely many Bregman firmly nonexpansive operators in a reflexive Banach space:

$$
\begin{aligned}
& x_{0} \in E \\
& Q_{0}^{i}=E, \quad i=1,2, \ldots, N \\
& u_{n} \in C \text { such that } \\
& y_{n}^{i}=T_{i}\left(x_{n}+e_{n}^{i}\right), \\
& Q_{n+1}^{i} \\
& \quad=\left\{z \in Q_{n}^{i}:\left\langle\nabla f\left(x_{n}+e_{n}^{i}\right)-\nabla f\left(y_{n}^{i}\right), z-y_{n}^{i}\right\rangle \leq 0\right\}, \\
& C_{n}=\bigcap_{i=1}^{N} C_{n}^{i}, \\
& x_{n+1}=P_{C_{n+1}}^{f} x_{0}, \quad n \geq 0 .
\end{aligned}
$$

Under some suitable conditions, they proved that the sequence generated by (9) converges strongly to $\bigcap_{i=1}^{N} F\left(T_{i}\right)$ and applied the result for the solution of convex feasibility and equilibrium problems.

In 2011, Chen et al. [11] introduced the concept of weak Bregman relatively nonexpansive mappings in a reflexive Banach space and gave an example to illustrate the existence of a weak Bregman relatively nonexpansive mapping and the difference between a weak Bregman relatively nonexpansive mapping and a Bregman relatively nonexpansive mapping. They also proved strong convergence of the sequences generated by the constructed algorithms with errors for finding a fixed point of weak Bregman relatively nonexpansive mappings and Bregman relatively nonexpansive mappings under some suitable conditions.

Recently in 2014, Alghamdi et al. [12] proved a strong convergence theorem for the common fixed point of finite family of quasi-Bregman nonexpansive mappings. Pang et al. [13] proved weak convergence theorems for Bregman relatively nonexpansive mappings, while Zegeye and Shahzad in $[14,15]$ proved a strong convergence theorem for the common fixed point of finite family of right Bregman strongly nonexpansive mappings and Bregman weak relatively nonexpansive mappings in reflexive Banach space, respectively.

In 2015 Kumam et al. [16] introduced the following algorithm:

$$
\begin{aligned}
x_{1} & =x \in C \\
z_{n} & =\operatorname{Res}_{g}^{f}\left(x_{n}\right) \\
y_{n} & =\nabla f^{*}\left(\beta_{n} \nabla f^{*}\left(x_{n}\right)+\left(1-\beta_{n}\right) \nabla f^{*}\left(T_{n}\left(z_{n}\right)\right)\right) \\
x_{n+1} & =\nabla f^{*}\left(\alpha_{n} \nabla f^{*}\left(x_{n}\right)+\left(1-\alpha_{n}\right) \nabla f^{*}\left(T_{n}\left(y_{n}\right)\right)\right),
\end{aligned}
$$

where $T_{n}, n \in \mathbb{N}$, is a Bregman strongly nonexpansive mapping. They proved that the sequence $\left\{x_{n}\right\}$ which is generated by algorithm (10) converges strongly to the point $P_{\Omega}^{f} x$, where $\Omega:=F(T) \cap \operatorname{EP}(g)$.

Motivated and inspired by the above works, in this paper, we prove a new strong convergence theorem for finite family of quasi-Bregman nonexpansive mapping and system of equilibrium problem in a real Banach space.

\section{Preliminaries}

Let $E$ be a real reflexive Banach space with the norm $\|\cdot\|$ and $E^{*}$ the dual space of $E$. Throughout this paper, we will assume $f: E \rightarrow(-\infty,+\infty]$ is a proper, lower semicontinuous, and convex function. We denote by dom $f:=\{x \in E: f(x)<$ $+\infty$ \} the domain of $f$.

Let $x \in \operatorname{int} \operatorname{dom} f$; the subdifferential of $f$ at $x$ is the convex set defined by

$$
\begin{aligned}
& \partial f(x) \\
& =\left\{x^{*} \in E^{*}: f(x)+\left\langle x^{*}, y-x\right\rangle \leq f(y), \forall y \in E\right\},
\end{aligned}
$$


where the Fenchel conjugate of $f$ is the function $f^{*}: E^{*} \rightarrow$ $(-\infty,+\infty]$ defined by

$$
f^{*}\left(x^{*}\right)=\sup \left\{\left\langle x^{*}, x\right\rangle-f(x): x \in E\right\} .
$$

We know that the Young-Fenchel inequality holds:

$$
\left\langle x^{*}, x\right\rangle \leq f(x)+f^{*}\left(x^{*}\right), \quad \forall x \in E, x^{*} \in E^{*} .
$$

A function $f$ on $E$ is coercive [17] if the sublevel set of $f$ is bounded; equivalently,

$$
\lim _{\|x\| \rightarrow+\infty} f(x)=+\infty .
$$

A function $f$ on $E$ is said be strongly coercive [18] if

$$
\lim _{\|x\| \rightarrow+\infty} \frac{f(x)}{\|x\|}=+\infty \text {. }
$$

For any $x \in \operatorname{int} \operatorname{dom} f$ and $y \in E$, the right-hand derivative of $f$ at $x$ in the direction $y$ is defined by

$$
f^{\circ}(x, y):=\lim _{t \rightarrow 0^{+}} \frac{f(x+t y)-f(x)}{t} .
$$

The function $f$ is said to be Gâteaux differentiable at $x$ if $\lim _{t \rightarrow 0^{+}}((f(x+t y)-f(x)) / t)$ exists for any $y$. In this case, $f^{\circ}(x, y)$ coincides with $\nabla f(x)$, the value of the gradient $\nabla f$ of $f$ at $x$. The function $f$ is said to be Gâteaux differentiable if it is Gâteaux differentiable for any $x \in \operatorname{int} \operatorname{dom} f$. The function $f$ is said to be Fréchet differentiable at $x$ if this limit is attained uniformly in $\|y\|=1$. Finally, $f$ is said to be uniformly Fréchet differentiable on a subset $C$ of $E$ if the limit is attained uniformly for $x \in C$ and $\|y\|=1$. It is known that if $f$ is Gâteaux differentiable (resp., Fréchet differentiable) on int $\operatorname{dom} f$, then $f$ is continuous and its Gâteaux derivative $\nabla f$ is norm-to-weak ${ }^{*}$ continuous (resp., continuous) on int $\operatorname{dom} f$ (see also $[19,20]$ ). We will need the following results.

Lemma 1 (see [21]). If $f: E \rightarrow \mathbb{R}$ is uniformly Fréchet differentiable and bounded on bounded subsets of $E$, then $\nabla f$ is uniformly continuous on bounded subsets of $E$ from the strong topology of $E$ to the strong topology of $E^{*}$.

Definition 2 (see [22]). The function $f$ is said to be

(i) essentially smooth, if $\partial f$ is both locally bounded and single-valued on its domain,

(ii) essentially strictly convex, if $(\partial f)^{-1}$ is locally bounded on its domain and $f$ is strictly convex on every convex subset of $\operatorname{dom} \partial f$,

(iii) Legendre, if it is both essentially smooth and essentially strictly convex.

Remark 3. Let $E$ be a reflexive Banach space. Then we have the following:

(i) $f$ is essentially smooth if and only if $f^{*}$ is essentially strictly convex (see [22], Theorem 5.4).

(ii) $(\partial f)^{-1}=\partial f^{*}($ see $[20])$. (iii) $f$ is Legendre if and only if $f^{*}$ is Legendre (see [22], Corollary 5.5).

(iv) If $f$ is Legendre, then $\nabla f$ is a bijection satisfying $\nabla f=\left(\nabla f^{*}\right)^{-1}, \operatorname{ran} \nabla f=\operatorname{dom} \nabla f^{*}=\operatorname{int} \operatorname{dom} f^{*}$, and $\operatorname{ran} \nabla f^{*}=\operatorname{dom} f=\operatorname{int} \operatorname{dom} f$ (see [22], Theorem 5.10).

The following result was proved in [23] (see also [24]).

Lemma 4. Let $E$ be a Banach space, let $r>0$ be a constant, let $\rho_{r}$ be the gauge of uniform convexity of $g$, and let $g: E \rightarrow \mathbb{R}$ be a convex function which is uniformly convex on bounded subsets of $E$. Then,

(i) for any $x, y \in B_{r}$ and $\alpha \in(0,1)$,

$$
\begin{aligned}
g(\alpha x+(1-\alpha) y) \leq & \alpha g(x)+(1-\alpha) g(y) \\
& -\alpha(1-\alpha) \rho_{r}(\|x-y\|),
\end{aligned}
$$

(ii) for any $x, y \in B_{r}$,

$$
\rho_{r}(\|x-y\|) \leq D_{g}(x, y),
$$

(iii) if, in addition, $g$ is bounded on bounded subsets and uniformly convex on bounded subsets of $E$ then, for any $x \in E, y^{*}, z^{*} \in B_{r}$, and $\alpha \in(0,1)$,

$$
\begin{aligned}
& V_{g}\left(x, \alpha y^{*}+(1-\alpha) z^{*}\right) \\
& \leq \alpha V_{g}\left(x, y^{*}\right)+(1-\alpha) V_{g}\left(x, z^{*}\right) \\
& -\alpha(1-\alpha) \rho_{r}^{*}\left(\left\|y^{*}-x^{*}\right\|\right) .
\end{aligned}
$$

Lemma 5 (see [25]). Let $E$ be a Banach space, let $r>0$ be a constant, and let $f: E \rightarrow \mathbb{R}$ be a continuous and convex function which is uniformly convex on bounded subsets of $E$. Then

$$
f\left(\sum_{k=0}^{\infty} \alpha_{k} x_{k}\right) \leq \sum_{k=0}^{\infty} \alpha_{k} f\left(x_{k}\right)-\alpha_{i} \alpha_{j} \rho_{r}\left(\left\|x_{i}-x_{j}\right\|\right),
$$

for all $i, j \in \mathbb{N} \cup\{0\}, x_{k} \in B_{r}, \alpha_{k} \in(0,1)$, and $k \in \mathbb{N} \cup\{0\}$ with $\sum_{k=0}^{\infty} \alpha_{k}=1$, where $\rho_{r}$ is the gauge of uniform convexity of $f$.

We know the following two results; see [18].

Theorem 6. Let $E$ be a reflexive Banach space and let $f: E \rightarrow$ $\mathbb{R}$ be a convex function which is bounded on bounded subsets of $E$. Then the following assertions are equivalent:

(1) $f$ is strongly coercive and uniformly convex on bounded subsets of $E$.

(2) $\operatorname{dom} f^{*}=E^{*}, f^{*}$ is bounded on bounded subsets and uniformly smooth on bounded subsets of $E^{*}$.

(3) $\operatorname{dom} f^{*}=E^{*}, f^{*}$ is Fréchet differentiable and $\nabla f$ is uniformly norm-to-norm continuous on bounded subsets of $E^{*}$. 
Theorem 7. Let $E$ be a reflexive Banach space and let $f: E \rightarrow$ $\mathbb{R}$ be a continuous convex function which is strongly coercive. Then the following assertions are equivalent:

(1) $f$ is bounded on bounded subsets and uniformly smooth on bounded subsets of E.

(2) $f^{*}$ is Fréchet differentiable and $f^{*}$ is uniformly normto-norm continuous on bounded subsets of $E^{*}$.

(3) $\operatorname{dom} f^{*}=E^{*}, f^{*}$ is strongly coercive and uniformly convex on bounded subsets of $E^{*}$. [27]).

The following result was first proved in [26] (see also

Lemma 8. Let $E$ be a reflexive Banach space, let $f: E \rightarrow \mathbb{R}$ be a strongly coercive Bregman function, and let $V$ be the function defined by

$$
\begin{aligned}
V\left(x, x^{*}\right)=f(x)-\left\langle x, x^{*}\right\rangle+f^{*}\left(x^{*}\right) & \\
& \\
& x \in E, x^{*} \in E^{*} .
\end{aligned}
$$

Then the following assertions hold:

(1) $D_{f}\left(x, \nabla f\left(x^{*}\right)\right)=V\left(x, x^{*}\right)$ for all $x \in E$ and $x^{*} \in E^{*}$.

(2) $V\left(x, x^{*}\right)+\left\langle\nabla f^{*}\left(x^{*}\right)-x, y^{*}\right\rangle \leq V\left(x, x^{*}+y^{*}\right)$ for all $x \in E$ and $x^{*}, y^{*} \in E^{*}$.

Examples of Legendre functions were given in $[22,28]$. One important and interesting Legendre function is $(1 / p) \|$. $\|^{p}(1<p<\infty)$ when $E$ is a smooth and strictly convex Banach space. In this case the gradient $\nabla f$ of $f$ is coincident with the generalized duality mapping of $E$; that is, $\nabla f=$ $J_{p}(1<p<\infty)$. In particular, $\nabla f=I$, the identity mapping in Hilbert spaces. In the rest of this paper, we always assume that $f: E \rightarrow(-\infty,+\infty]$ is Legendre.

Concerning the Bregman projection, the following are well known.

Lemma 9 (see [26]). Let $C$ be a nonempty, closed, and convex subset of a reflexive Banach space E. Let $f: E \rightarrow \mathbb{R}$ be a Gâteaux differentiable and totally convex function and let $x \in E$. Then

(a) $z=P_{C}^{f}(x)$ if and only if $\langle\nabla f(x)-\nabla f(z), y-z\rangle \leq$ $0, \forall y \in C$.

(b) $D_{f}\left(y, P_{C}^{f}(x)\right)+D_{f}\left(P_{C}^{f}(x), x\right) \leq D_{f}(y, x), \forall x \in$ $E, y \in C$.

Let $f: E \rightarrow(-\infty,+\infty]$ be a convex and Gâteaux differentiable function. The modulus of total convexity of $f$ at $x \in \operatorname{int} \operatorname{dom} f$ is the function $v_{f}(x, \cdot):[0,+\infty) \rightarrow[0,+\infty]$ defined by

$$
\begin{aligned}
& v_{f}(x, t) \\
& \quad:=\inf \left\{D_{f}(y, x): y \in \operatorname{dom} f,\|y-x\|=t\right\},
\end{aligned}
$$

The function $f$ is called totally convex at $x$ if $v_{f}(x, t)>0$ whenever $t>0$. The function $f$ is called totally convex if it is totally convex at any point $x \in \operatorname{int} \operatorname{dom} f$ and is said to be totally convex on bounded sets if $v_{f}(B, t)>0$ for any nonempty bounded subset $B$ of $E$ and $t>0$, where the modulus of total convexity of the function $f$ on the set $B$ is the function $v_{f}$ : int dom $f \times[0,+\infty) \rightarrow[0,+\infty]$ defined by

$$
v_{f}(B, t):=\inf \left\{v_{f}(x, t): x \in B \cap \operatorname{dom} f\right\} .
$$

Lemma 10 (see [29]). If $x \in \operatorname{dom} f$, then the following statements are equivalent:

(i) The function $f$ is totally convex at $x$.

(ii) For any sequence $\left\{y_{n}\right\} \subset \operatorname{dom} f$,

$$
\lim _{n \rightarrow+\infty} D_{f}\left(y_{n}, x\right)=0 \Longrightarrow \lim _{n \rightarrow+\infty}\left\|y_{n}-x\right\|=0 .
$$

Recall that the function $f$ is called sequentially consistent [26] if for any two sequences $\left\{x_{n}\right\}$ and $\left\{y_{n}\right\}$ in $E$ such that the first one is bounded

$$
\lim _{n \rightarrow+\infty} D_{f}\left(y_{n}, x_{n}\right)=0 \Longrightarrow \lim _{n \rightarrow+\infty}\left\|y_{n}-x_{n}\right\|=0 .
$$

Lemma 11 (see [30]). The function $f$ is totally convex on bounded sets if and only if the function $f$ is sequentially consistent.

Lemma 12 (see [31]). Let $f: E \rightarrow \mathbb{R}$ be a Gâteaux differentiable and totally convex function. If $x_{0} \in E$ and the sequence $\left\{D_{f}\left(x_{n}, x_{0}\right)\right\}$ is bounded, then the sequence $\left\{x_{n}\right\}$ is bounded too.

Lemma 13 (see [31]). Let $f: E \rightarrow \mathbb{R}$ be a Gâteaux differentiable and totally convex function, $x_{0} \in E$, and let $C$ be a nonempty, closed, and convex subset of E. Suppose that the sequence $\left\{x_{n}\right\}$ is bounded and any weak subsequential limit of $\left\{x_{n}\right\}$ belongs to C. If $D_{f}\left(x_{n}, x_{0}\right) \leq D_{f}\left(P_{C}^{f}\left(x_{0}\right), x_{0}\right)$ for any $n \in \mathbb{R}$, then $\left\{x_{n}\right\}$ converges strongly to $P_{C}^{f}\left(x_{0}\right)$.

Lemma 14 (see [32]). Let $E$ be a real reflexive Banach space, let $f: E \rightarrow(-\infty,+\infty]$ be a proper lower semicontinuous function, and then $f^{*}: E^{*} \rightarrow(-\infty,+\infty]$ is a proper weak ${ }^{*}$ lower semicontinuous and convex function. Thus, for all $z \in E$, one has

$$
D_{f}\left(z, \nabla f^{*}\left(\sum_{i=1}^{N} t_{i} \nabla f\left(x_{i}\right)\right)\right) \leq \sum_{i=1}^{N} t_{i} D_{f}\left(z, x_{i}\right) .
$$

In order to solve the equilibrium problem, let us assume that a bifunction $g: C \times C \rightarrow \mathbb{R}$ satisfies the following conditions [1]:

(A1) $g(x, x)=0, \forall x \in C$.

(A2) $g$ is monotone; that is, $g(x, y)+g(y, x) \leq 0, \forall x, y \in$ C.

(A3) $\lim \sup _{t \downarrow 0} g(x+t(z-x), y) \leq g(x, y) \forall x, z, y \in C$.

(A4) The function $y \mapsto g(x, y)$ is convex and lower semicontinuous. 
The resolvent of a bifunction $g$ [2] is the operator $\operatorname{Res}_{g}^{f}: E \rightarrow$ $2^{C}$ defined by

$$
\begin{aligned}
& \operatorname{Res}_{g}^{f}(x)=\{z \in C: g(z, y) \\
& \quad+\langle\nabla f(z)-\nabla f(x), y-z\rangle \geq 0, \forall y \in C\} .
\end{aligned}
$$

From Lemma 1 , in [33], if $f:(-\infty,+\infty]$ is a strongly coercive and Gâteaux differentiable function and $g$ satisfies conditions (A1)-(A4), then $\operatorname{dom}\left(\operatorname{Res}_{g}^{f}\right)=E$. The following lemma gives some characterization of the resolvent $\operatorname{Res}_{g}^{f}$.

Lemma 15 (see [33]). Let $E$ be a real reflexive Banach space and let $C$ be a nonempty closed convex subset of $E$. Let $f: E \rightarrow$ $(-\infty,+\infty]$ be a Legendre function. If the bifunction $g: C \times$ $C \rightarrow \mathbb{R}$ satisfies the conditions (A1)-(A4), then, the following hold:

(i) $\operatorname{Res}_{g}^{f}$ is single-valued.

(ii) $\operatorname{Res}_{g}^{f}$ is a Bregman firmly nonexpansive operator.

(iii) $F\left(\operatorname{Res}_{g}^{f}\right)=\operatorname{EP}(g)$.

(iv) $\mathrm{EP}(g)$ is closed and convex subset of C.

(v) For all $x \in E$ and for all $q \in F\left(\operatorname{Res}_{g}^{f}\right)$, one has

$$
D_{f}\left(q, \operatorname{Res}_{g}^{f}(x)\right)+D_{f}\left(\operatorname{Res}_{g}^{f}(x), x\right) \leq D_{f}(q, x) .
$$

Lemma 16 (see [34]). Let $\left\{a_{n}\right\}$ be a sequence of nonnegative real numbers satisfying the following relation:

$$
a_{n+1} \leq\left(1-\alpha_{n}\right) a_{n}+\alpha_{n} \delta_{n}, \quad n \geq n_{0}
$$

where $\left\{\alpha_{n}\right\} \subset(0,1)$ and $\left\{\delta_{n}\right\}$ is a real sequence satisfying the following conditions:

$$
\begin{aligned}
\lim _{n \rightarrow \infty} \alpha_{n} & =0, \\
\sum_{n=1}^{\infty} & =\infty,
\end{aligned}
$$

$$
\text { as } \limsup _{n \rightarrow \infty} \delta_{n} \leq 0 \text {. }
$$

Then, $\lim _{n \rightarrow \infty} a_{n}=0$.

Lemma 17 (see [35]). Let $\left\{a_{n}\right\}$ be a sequence of real numbers such that there exists a subsequence $\left\{n_{i}\right\}$ of $\{n\}$ such that $a_{n_{i}}<$ $a_{n_{i}+1}$ for all $i \in \mathbb{N}$. Then there exists a nondecreasing sequence $\left\{m_{k}\right\} \subset \mathbb{N}$ such that $m_{k} \rightarrow \infty$ and the following properties are satisfied by all (sufficiently large) numbers $k \in \mathbb{N}$ :

$$
\begin{aligned}
a_{m_{k}} & \leq a_{m_{k}+1}, \\
a_{k} & \leq a_{m_{k}+1} .
\end{aligned}
$$

In fact, $m_{k}=\max \left\{j \leq k: a_{j}<a_{j+1}\right\}$.

\section{Main Results}

We now prove the following theorem.

Theorem 18. Let $C$ be a nonempty, closed, and convex subset of a real reflexive Banach space $E$ and $f: E \rightarrow \mathbb{R}$ a strongly coercive Legendre function which is bounded, uniformly Fréchet differentiable, and totally convex on bounded subset of E. For each $j=1,2, \ldots, m$, let $g_{j}$ be a bifunction from $C \times C$ to $\mathbb{R}$ satisfying (A1)-(A4) and let $\left\{T_{i=1}^{N}\right\}$ be a finite family of quasi-Bregman nonexpansive self-mapping of $C$ such that $F:=\bigcap_{i=1}^{N} F\left(T_{i}\right) \neq \emptyset$, where $F=F\left(T_{N} T_{N-1} T_{N-2} \cdots T_{2} T_{1}\right)=$ $F\left(T_{1} T_{N} T_{N-1} T_{N-2} \cdots T_{2}\right)=\cdots=F\left(T_{N-1} T_{N-2} \cdots T_{2} T_{1} T_{N}\right) \neq$ $\emptyset$ and $\Omega:=\left(\bigcap_{j=1}^{m} \operatorname{EP}\left(g_{j}\right)\right) \cap F \neq \emptyset$. Let $\left\{x_{n}\right\}_{n=1}^{\infty}$ be a sequence generated by $x_{1}=x \in C, C_{1}=C$, and

$$
\begin{aligned}
x_{1} & \in C \\
u_{j, n} & =\operatorname{Res}_{g_{j}}^{f} x_{n}, \quad j=1,2,3, \ldots, m \\
y_{n} & =P_{C}\left(\nabla f^{*}\left(\left(1-\alpha_{n}\right) \nabla f\left(u_{j, n}\right)\right)\right) \\
x_{n+1} & =P_{C}\left(\nabla f^{*}\left(\beta_{n} \nabla f\left(y_{n}\right)+\left(1-\beta_{n}\right) \nabla f\left(T_{[n]} y_{n}\right)\right)\right),
\end{aligned}
$$

where $T_{[n]}=T_{n(\bmod N)}$ and $\left\{\alpha_{n}\right\}_{n=1}^{\infty} \subset(0,1)$ and $\left\{\beta_{n}\right\}_{n=1}^{\infty} \subset$ $[c, d] \subset(0,1)$ satisfying $\lim _{n \rightarrow \infty} \alpha_{n}=0$ and $\sum_{n=1}^{\infty} \alpha_{n}=\infty$. Then $\left\{x_{n}\right\}_{n=1}^{\infty}$ converges strongly to $P_{\Omega}^{f}(x)$, where $P_{\Omega}^{f}$ is the Bregman projection of $C$ onto $\Omega$.

Proof. Let $p=P_{\Omega}^{f} \in \Omega$ from Lemma 15; we obtain

$$
D_{f}\left(p, u_{j, n}\right)=D_{f}\left(p, \operatorname{Res}_{g_{j}}^{f} x_{n}\right) \leq D_{f}\left(p, x_{n}\right) .
$$

Now from (32), we obtain

$$
\begin{aligned}
& D_{f}\left(p, y_{n}\right) \leq D_{f}\left(p, \nabla f^{*}\left(\left(1-\alpha_{n}\right) \nabla f\left(u_{j, n}\right)\right)\right) \\
& \quad=D_{f}\left(p, \nabla f^{*}\left(\alpha_{n} \nabla f(0)+\left(1-\alpha_{n}\right) \nabla f\left(u_{j, n}\right)\right)\right) \\
& \quad \leq \alpha_{n} D_{f}(p, 0)+\left(1-\alpha_{n}\right) D_{f}\left(p, u_{j, n}\right) \\
& \quad \leq \alpha_{n} D_{f}(p, 0)+\left(1-\alpha_{n}\right) D_{f}\left(p, x_{n}\right) .
\end{aligned}
$$

Also from (32), (26), and (34), we have

$$
\begin{aligned}
D_{f} & \left(p, x_{n+1}\right) \\
& \leq D_{f}\left(p, \nabla f^{*}\left(\left(1-\beta_{n}\right) \nabla f\left(y_{n}\right)+\beta_{n} \nabla f\left(T_{[n]} y_{n}\right)\right)\right) \\
& \leq\left(1-\beta_{n}\right) D_{f}\left(p, y_{n}\right)+\beta_{n} D_{f}\left(p, T_{[n]} y_{n}\right) \\
& \leq\left(1-\beta_{n}\right) D_{f}\left(p, y_{n}\right)+\beta_{n} D_{f}\left(p, y_{n}\right) \\
& =D_{f}\left(p, y_{n}\right) \leq \alpha_{n} D_{f}(p, 0)+\left(1-\alpha_{n}\right) D_{f}\left(p, x_{n}\right) \\
& \leq \max \left\{D_{f}(p, 0), D_{f}\left(p, x_{n}\right)\right\} .
\end{aligned}
$$

Thus, by induction we obtain

$$
D_{f}\left(p, x_{n+1}\right) \leq \max \left\{D_{f}(p, 0), D_{f}\left(p, x_{n}\right)\right\},
$$


which implies that $\left\{x_{n}\right\}$ is bounded and hence $\left\{y_{n}\right\},\left\{T_{[n]} y_{n}\right\}$, $\left\{T_{[n]} x_{n}\right\}$, and $\left\{u_{j, n}\right\}$ are all bounded for each $j=1,2, \ldots, m$. Now from (32) let $z_{n}:=\nabla f^{*}\left(\left(1-\alpha_{n}\right) \nabla f\left(u_{j, n}\right)\right)$. Furthermore since $\alpha_{n} \rightarrow 0$ as $n \rightarrow \infty$, we obtain

$$
\begin{aligned}
\left\|\nabla f\left(z_{n}\right)-\nabla f\left(u_{j, n}\right)\right\|=\alpha_{n}\left\|\left(-\nabla f\left(u_{j, n}\right)\right)\right\| & \longrightarrow 0 \\
\text { as } n & \longrightarrow \infty .
\end{aligned}
$$

Since $f$ is strongly coercive and uniformly convex on bounded subsets of $E, f^{*}$ is uniformly Fréchet differentiable on bounded sets. Moreover, $f^{*}$ is bounded on bounded sets; from (37), we obtain

$$
\lim _{n \rightarrow \infty}\left\|z_{n}-u_{j, n}\right\|=0
$$

On the other hand, in view of (3) in Theorem 6, we know that $\operatorname{dom} f^{*}=E^{*}$ and $f^{*}$ is strongly coercive and uniformly convex on bounded subsets. Let $s=\sup \left\{\left\|\nabla f\left(y_{n}\right)\right\|,\left\|\nabla f\left(T_{[n]} y_{n}\right)\right\|\right\}$ and $\rho_{s}^{*}: E^{*} \rightarrow \mathbb{R}$ be the gauge of uniform convexity of the conjugate function $f^{*}$. Now from (32) and Lemmas 4 and 8, we obtain

$$
\begin{aligned}
& D_{f}\left(p, y_{n}\right) \leq D_{f}\left(p, z_{n}\right)=V\left(p, \nabla f\left(z_{n}\right)\right) \\
& \leq V\left(p, \nabla f\left(z_{n}\right)+\alpha_{n} \nabla f(p)\right) \\
& +\alpha_{n}\left\langle-\nabla f(p), z_{n}-p\right\rangle \\
& =D_{f}\left(p, \nabla f^{*}\left(\left(1-\alpha_{n}\right) \nabla f\left(u_{j, n}\right)+\alpha_{n} \nabla f(p)\right)\right) \\
& +\alpha_{n} \nabla f(p)+\alpha_{n}\left\langle-\nabla f(p), z_{n}-p\right\rangle \\
& \leq \alpha_{n} D_{f}(p, p)+\left(1-\alpha_{n}\right) D_{f}\left(p, u_{j, n}\right) \\
& +\alpha_{n}\left\langle-\nabla f(p), z_{n}-p\right\rangle \\
& \leq\left(1-\alpha_{n}\right) D_{f}\left(p, x_{n}\right)+\alpha_{n}\left\langle-\nabla f(p), z_{n}-p\right\rangle \text {, } \\
& D_{f}\left(p, x_{n+1}\right) \\
& \leq D_{f}\left(p, \nabla f^{*}\left(\left(1-\beta_{n}\right) \nabla f\left(y_{n}\right)+\beta_{n} \nabla f\left(T_{[n]} y_{n}\right)\right)\right) \\
& =V\left(p,\left(1-\beta_{n}\right) \nabla f\left(y_{n}\right)+\beta_{n} \nabla f\left(T_{[n]} y_{n}\right)\right) \\
& =f(p)-\left\langle p,\left(1-\beta_{n}\right) \nabla f\left(y_{n}\right)+\beta_{n} \nabla f\left(T_{[n]} y_{n}\right)\right\rangle \\
& +f^{*}\left(\left(1-\beta_{n}\right) \nabla f\left(y_{n}\right)+\beta_{n} \nabla f\left(T_{[n]} y_{n}\right)\right) \\
& \leq\left(1-\beta_{n}\right) f(p)+\beta_{n} f(p) \\
& -\left(1-\beta_{n}\right)\left\langle p, \nabla f\left(y_{n}\right)\right\rangle-\beta_{n}\left\langle p, \nabla f\left(T_{[n]} y_{n}\right)\right\rangle \\
& +\left(1-\beta_{n}\right) f^{*}\left(\nabla f\left(T_{[n]} y_{n}\right)\right) \\
& +\beta_{n} f^{*}\left(\nabla f\left(T_{[n]} y_{n}\right)\right) \\
& -\beta_{n}\left(1-\beta_{n}\right) \rho_{s}^{*}\left(\left\|\nabla f\left(y_{n}\right)-\nabla f\left(T_{[n]} y_{n}\right)\right\|\right)
\end{aligned}
$$

$$
\begin{aligned}
= & \left(1-\beta_{n}\right) V\left(p, \nabla f\left(y_{n}\right)\right)+\beta_{n} V\left(p, \nabla f\left(T_{[n]} y_{n}\right)\right) \\
& -\beta_{n}\left(1-\beta_{n}\right) \rho_{s}^{*}\left(\left\|\nabla f\left(y_{n}\right)-\nabla f\left(T_{[n]} y_{n}\right)\right\|\right) \\
= & \left(1-\beta_{n}\right) D_{f}\left(p, y_{n}\right)+\beta_{n} D_{f}\left(p, T_{[n]} y_{n}\right) \\
& -\beta_{n}\left(1-\beta_{n}\right) \rho_{s}^{*}\left(\left\|\nabla f\left(y_{n}\right)-\nabla f\left(T_{[n]} y_{n}\right)\right\|\right) \\
\leq & \left(1-\beta_{n}\right) D_{f}\left(p, y_{n}\right)+\beta_{n} D_{f}\left(p, y_{n}\right) \\
& -\beta_{n}\left(1-\beta_{n}\right) \rho_{s}^{*}\left(\left\|\nabla f\left(y_{n}\right)-\nabla f\left(T_{[n]} y_{n}\right)\right\|\right) \\
= & D_{f}\left(p, y_{n}\right) \\
& -\beta_{n}\left(1-\beta_{n}\right) \rho_{s}^{*}\left(\left\|\nabla f\left(y_{n}\right)-\nabla f\left(T_{[n]} y_{n}\right)\right\|\right) \\
\leq & \left(1-\alpha_{n}\right) D_{f}\left(p, x_{n}\right)+\alpha_{n}\left\langle-\nabla f(p), z_{n}-p\right\rangle \\
& -\beta_{n}\left(1-\beta_{n}\right) \rho_{s}^{*}\left(\left\|\nabla f\left(y_{n}\right)-\nabla f\left(T_{[n]} y_{n}\right)\right\|\right) \\
\leq & \left(1-\alpha_{n}\right) D_{f}\left(p, x_{n}\right)+\alpha_{n}\left\langle-\nabla f(p), z_{n}-p\right\rangle .
\end{aligned}
$$

Now, we consider two cases.

Case 1. Suppose that there exists $n_{0} \in \mathbb{N}$ such that $\left\{D_{f}\left(p, x_{n}\right)\right\}$ is nonincreasing. In this situation $\left\{D_{f}\left(p, x_{n}\right)\right\}$ is convergent. Then from (40) we obtain

$$
\begin{aligned}
& \beta_{n}\left(1-\beta_{n}\right) \rho_{s}^{*}\left(\left\|\nabla f\left(y_{n}\right)-\nabla f\left(T_{[n]} y_{n}\right)\right\|\right) \longrightarrow 0 \\
& \text { as } n \longrightarrow \infty,
\end{aligned}
$$

which implies, by the property of $\rho_{s}$ and since $\beta_{n} \in[c, d] \subset$ $(0,1)$,

$$
\lim _{n \rightarrow \infty}\left\|\nabla f\left(y_{n}\right)-\nabla f\left(T_{[n]} y_{n}\right)\right\|=0
$$

Since $f$ is strongly coercive and uniformly convex on bounded subsets of $E, f^{*}$ is uniformly Fréchet differentiable on bounded sets. Moreover, $f^{*}$ is bounded on bounded sets; from (43), we obtain

$$
\lim _{n \rightarrow \infty}\left\|y_{n}-T_{[n]} y_{n}\right\|=0
$$

Now from (4), we obtain

$$
\begin{aligned}
D_{f}\left(y_{n}, T_{[n]} y_{n}\right) \\
=D_{f}\left(p, T_{[n]} y_{n}\right)-D_{f}\left(p, y_{n}\right) \\
\quad+\left\langle\nabla f\left(T_{[n]} y_{n}\right)-\nabla f\left(y_{n}\right), p-y_{n}\right\rangle \\
\leq D_{f}\left(p, y_{n}\right)-D_{f}\left(p, y_{n}\right) \\
\quad+\left\langle\nabla f\left(T_{[n]} y_{n}\right)-\nabla f\left(y_{n}\right), p-y_{n}\right\rangle,
\end{aligned}
$$

and therefore

$$
\begin{aligned}
& D_{f}\left(y_{n}, T_{[n]} y_{n}\right) \\
& \quad \leq\left\|\nabla f\left(y_{n}\right)-\nabla f\left(T_{[n]} y_{n}\right)\right\|\left\|p-y_{n}\right\| \longrightarrow 0
\end{aligned}
$$


Also, from (28) in Lemma 15, we have

$$
\begin{aligned}
D_{f}\left(x_{n}, u_{j, n}\right) & =D_{f}\left(x_{n}, \operatorname{Res}_{g_{j}}^{f} x_{n}\right) \\
& \leq D_{f}\left(p, \operatorname{Res}_{g_{j}}^{f} x_{n}\right)-D_{f}\left(p, x_{n}\right) \\
& \leq D_{f}\left(p, x_{n}\right)-D_{f}\left(p, x_{n}\right) \longrightarrow 0
\end{aligned}
$$

as $n \longrightarrow \infty$.

Then, we have from Lemma 10 that

$$
\lim _{n \rightarrow \infty}\left\|x_{n}-u_{j, n}\right\|=0 .
$$

Also, from (b) of Lemma 9, we have

$$
\begin{aligned}
& D_{f}\left(y_{n}, P_{C} z_{n}\right)=D_{f}\left(y_{n}, z_{n}\right) \\
& \quad=D_{f}\left(y_{n}, \nabla f^{*}\left(\nabla f(0)+\left(1-\alpha_{n}\right) \nabla f\left(u_{j, n}\right)\right)\right) \\
& \quad \leq \alpha_{n} D_{f}\left(y_{n}, 0\right)+\left(1-\alpha_{n}\right) D_{f}\left(y_{n}, u_{j, n}\right) \\
& \quad \leq \alpha_{n} D_{f}\left(y_{n}, 0\right)+\left(1-\alpha_{n}\right) D_{f}\left(u_{j, n}, u_{j, n}\right) \longrightarrow 0 \\
& \text { as } n \longrightarrow \infty .
\end{aligned}
$$

Then, we have from Lemma 10 that

$$
\lim _{n \rightarrow \infty}\left\|y_{n}-z_{n}\right\|=0 .
$$

From (38) and (48), we obtain

$$
\lim _{n \rightarrow \infty}\left\|x_{n}-z_{n}\right\|=0 \text {. }
$$

From (50) and (51), we obtain

$$
\lim _{n \rightarrow \infty}\left\|x_{n}-y_{n}\right\|=0 \text {. }
$$

Since $f$ is strongly coercive and uniformly convex on bounded subsets of $E, f^{*}$ is uniformly Fréchet differentiable on bounded sets. Moreover, $f^{*}$ is bounded on bounded sets; from (52), we obtain

$$
\lim _{n \rightarrow \infty}\left\|\nabla f\left(x_{n}\right)-\nabla f\left(z_{n}\right)\right\|=0 .
$$

Also from (44) and (52)

$$
\lim _{n \rightarrow \infty}\left\|x_{n}-T_{[n]} y_{n}\right\|=0 \text {. }
$$

Now from (4) and (34), we obtain

$$
\begin{aligned}
D_{f}\left(x_{n}, y_{n}\right)= & D_{f}\left(p, y_{n}\right)-D_{f}\left(p, x_{n}\right) \\
& +\left\langle\nabla f\left(x_{n}\right)-\nabla f\left(y_{n}\right), p-x_{n}\right\rangle \\
\leq & \alpha_{n} D_{f}(p, 0)+\left(1-\alpha_{n}\right) D_{f}\left(p, x_{n}\right) \\
& -D_{f}\left(p, x_{n}\right) \\
& +\left\langle\nabla f\left(x_{n}\right)-\nabla f\left(y_{n}\right), p-x_{n}\right\rangle \\
= & \alpha_{n}\left(D_{f}(p, 0)-D_{f}\left(p, x_{n}\right)\right) \\
& +\left\langle\nabla f\left(x_{n}\right)-\nabla f\left(y_{n}\right), p-x_{n}\right\rangle ;
\end{aligned}
$$

therefore, from (53), we obtain

$$
\begin{aligned}
D_{f}\left(x_{n}, y_{n}\right) \leq & \alpha_{n}\left(D_{f}(p, 0)-D_{f}\left(p, x_{n}\right)\right) \\
& +\left\|\nabla f\left(x_{n}\right)-\nabla f\left(y_{n}\right)\right\|\left\|p-x_{n}\right\| \\
& \rightarrow 0 \\
& \text { as } n \longrightarrow \infty .
\end{aligned}
$$

Also

$$
\begin{aligned}
& D_{f}\left(x_{n}, T_{[n]} y_{n}\right) \\
&=D_{f}\left(p, T_{[n]} y_{n}\right)-D_{f}\left(p, x_{n}\right) \\
& \quad+\left\langle\nabla f\left(x_{n}\right)-\nabla f\left(T_{[n]} y_{n}\right), p-x_{n}\right\rangle \\
& \leq D_{f}\left(p, y_{n}\right)-D_{f}\left(p, x_{n}\right) \\
& \quad+\left\langle\nabla f\left(x_{n}\right)-\nabla f\left(T_{[n]} y_{n}\right), p-x_{n}\right\rangle \\
& \leq \alpha_{n} D_{f}(p, 0)+\left(1-\alpha_{n}\right)-D_{f}\left(p, x_{n}\right) \\
&+\left\langle\nabla f\left(x_{n}\right)-\nabla f\left(T_{[n]} y_{n}\right), p-x_{n}\right\rangle \\
&= \alpha_{n}\left(D_{f}(p, 0)-D_{f}\left(p, x_{n}\right)\right) \\
&+\left\langle\nabla f\left(x_{n}\right)-\nabla f\left(T_{[n]} y_{n}\right), p-x_{n}\right\rangle ;
\end{aligned}
$$

thus

$$
\begin{aligned}
D_{f}\left(x_{n}, T_{[n]} y_{n}\right) \\
\leq \alpha_{n}\left|D_{f}(p, 0)-D_{f}\left(p, x_{n}\right)\right| \\
\quad+\left\|\nabla f\left(T_{[n]} y_{n}\right)-\nabla f\left(x_{n}\right)\right\|\left\|p-x_{n}\right\| \longrightarrow 0
\end{aligned}
$$
as $n \longrightarrow \infty$

Also, from (56)

$$
D_{f}\left(T_{[n]} x_{n}, T_{[n]} y_{n}\right) \leq D_{f}\left(x_{n}, y_{n}\right) \longrightarrow 0
$$

as $n \longrightarrow \infty$

Then, we have from Lemma 10 that

$$
\lim _{n \rightarrow \infty}\left\|T_{[n]} x_{n}-T_{[n]} y_{n}\right\|=0 .
$$

Then from (32) and (44), we have

$$
\begin{aligned}
& \left\|\nabla f\left(x_{n+1}\right)-\nabla f\left(y_{n}\right)\right\| \\
& \quad=\beta_{n}\left\|\nabla f\left(T_{[n]} y_{n}\right)-\nabla f\left(y_{n}\right)\right\| \longrightarrow 0 \quad \text { as } n \longrightarrow \infty .
\end{aligned}
$$

This implies

$$
\begin{aligned}
\left\|x_{n+1}-y_{n}\right\| & \longrightarrow 0 \quad \text { as } n \longrightarrow \infty \\
\left\|x_{n}-T_{[n]} x_{n}\right\| \leq & \left\|x_{n}-y_{n}\right\|+\left\|y_{n}-T_{[n]} y_{n}\right\| \\
& +\left\|T_{[n]} y_{n}-T_{[n]} x_{n}\right\|
\end{aligned}
$$

from (44), (52), and (60), we obtain

$$
\lim _{n \rightarrow \infty}\left\|x_{n}-T_{[n]} x_{n}\right\|=0 .
$$


This implies that

$$
\lim _{n \rightarrow \infty}\left\|\nabla f\left(x_{n}\right)-\nabla f\left(T_{[n]} x_{n}\right)\right\|=0 .
$$

Also from (52) and (62), we obtain

$$
\begin{aligned}
\left\|x_{n+1}-x_{n}\right\| \leq\left\|x_{n+1}-y_{n}\right\|+\left\|y_{n}-x_{n}\right\| & \longrightarrow 0 \\
& \text { as } n \longrightarrow \infty .
\end{aligned}
$$

But

$$
\begin{gathered}
\left\|x_{n+N}-x_{n}\right\| \leq\left\|x_{n+N}-x_{n+N-1}\right\|+\left\|x_{n+N-1}-x_{n+N-2}\right\| \\
+\cdots+\left\|x_{n+1}-x_{n}\right\| \longrightarrow 0
\end{gathered}
$$

as $n \rightarrow \infty$. Hence

$$
\lim _{n \rightarrow \infty}\left\|x_{n+N}-x_{n}\right\|=0
$$

From the uniformly continuous $\nabla f$, we have from (66) that

$$
\lim _{n \rightarrow \infty}\left\|\nabla f\left(x_{n+1}\right)-\nabla f\left(x_{n}\right)\right\|=0
$$

From (4), (35), and (69), we obtain

$$
\begin{aligned}
D_{f}\left(x_{n}, x_{n+1}\right)= & D_{f}\left(p, x_{n+1}\right)-D_{f}\left(p, x_{n}\right) \\
& +\left\langle\nabla f\left(x_{n}\right)-\nabla f\left(x_{n+}\right), p-x_{n}\right\rangle \\
\leq & \alpha_{n} D_{f}(p, 0)+\left(1-\alpha_{n}\right) D_{f}\left(p, x_{n}\right) \\
& -D_{f}\left(p, x_{n}\right) \\
& +\left\langle\nabla f\left(x_{n}\right)-\nabla f\left(x_{n+1}\right), p-x_{n}\right\rangle,
\end{aligned}
$$

which implies

$$
D_{f}\left(x_{n}, x_{n+1}\right) \leq \alpha_{n}\left|D_{f}(p, 0)-D_{f}\left(p, x_{n}\right)\right|+\left\|\nabla f\left(x_{n+1}\right)-\nabla f\left(x_{n}\right)\right\|\left\|p-x_{n}\right\| \longrightarrow 0 \quad \text { as } n \longrightarrow \infty \text {. }
$$

Also from quasi-Bregman nonexpansivity of $T_{[n]}$, we have

$$
D_{f}\left(T_{[n]} x_{n}, T_{[n]} x_{n+1}\right) \leq D_{f}\left(x_{n}, x_{n+1}\right) \longrightarrow 0
$$$$
\text { as } n \longrightarrow \infty \text {, }
$$

which implies

$$
\lim _{n \rightarrow \infty}\left\|T_{[n]} x_{n}-T_{[n]} x_{n+1}\right\|=0
$$

and from the uniform continuous $\nabla f$, we obtain

$$
\lim _{n \rightarrow \infty}\left\|\nabla f\left(T_{[n]} x_{n}\right)-\nabla f\left(T_{[n]} x_{n+1}\right)\right\|=0 .
$$

Also from (4) and (64), we obtain

$$
\begin{aligned}
D_{f} & \left(x_{n}, T_{[n]} x_{n}\right) \\
= & D_{f}\left(p, T_{[n]} x_{n}\right)-D_{f}\left(p, x_{n}\right) \\
& +\left\langle\nabla f\left(x_{n}\right)-\nabla f\left(T_{[n]} x_{n}\right), p-x_{n}\right\rangle \\
\leq & D_{f}\left(p, x_{n}\right)-D_{f}\left(p, x_{n}\right) \\
\quad & +\left\langle\nabla f\left(x_{n}\right)-\nabla f\left(T_{[n]} x_{n}\right), p-x_{n}\right\rangle \\
\leq & \left\|\nabla f\left(T_{[n]} x_{n}\right)-\nabla f\left(x_{n}\right)\right\|\left\|p-x_{n}\right\| \rightarrow 0
\end{aligned}
$$

From (64), (66), and (73), we obtain

$$
\begin{aligned}
&\left\|x_{n}-T_{[n+1]} x_{n}\right\| \leq\left\|x_{n}-x_{n+1}\right\|+\left\|x_{n+1}-T_{[n+1]} x_{n+1}\right\| \\
&+\left\|T_{[n+1]} x_{n+1}-T_{[n+1]} x_{n}\right\| \longrightarrow 0 \\
& \text { as } n \longrightarrow \infty,
\end{aligned}
$$

which from uniform continuous $\nabla f$ implies

$$
\lim _{n \rightarrow \infty}\left\|\nabla f\left(T_{[n]} x_{n}\right)-\nabla f\left(T_{[n+1]} x_{n}\right)\right\|=0,
$$

and from (4) and (77), we obtain

$$
\begin{aligned}
D_{f}\left(x_{n}, T_{[n+1]} x_{n}\right) & \\
\leq & D_{f}\left(p, T_{[n+1]} x_{n}\right)-D_{f}\left(p, x_{n}\right) \\
\quad & +\left\langle\nabla f\left(x_{n}\right)-\nabla f\left(T_{[n+1]} x_{n}\right), p-x_{n}\right\rangle \\
\leq & D_{f}\left(p, x_{n}\right)-D_{f}\left(p, x_{n}\right) \\
\quad+\left\|\nabla f\left(T_{[n+1]} x_{n}\right)-\nabla f\left(x_{n}\right)\right\|\left\|p-x_{n}\right\| & \longrightarrow 0 \\
& \text { as } n \longrightarrow \infty .
\end{aligned}
$$

From (4), (71), (77), and (78)

$$
\begin{aligned}
D_{f} & \left(x_{n+1}, T_{[n+1]} x_{n}\right) \\
& =D_{f}\left(x_{n+1}, x_{n}\right)+D_{f}\left(x_{n}, T_{[n+1]} x_{n}\right)
\end{aligned}
$$$$
+\left\langle\nabla f\left(T_{[n+1]} x_{n}\right)-\nabla f\left(x_{n}\right), x_{n}-x_{n+1}\right\rangle
$$$$
\leq D_{f}\left(x_{n+1}, x_{n}\right)+D_{f}\left(x_{n}, T_{[n+1]} x_{n}\right)
$$

$$
+\left\|\nabla f\left(T_{[n+1]} x_{n}\right)-\nabla f\left(x_{n}\right)\right\|\left\|x_{n}-x_{n+1}\right\| \longrightarrow 0
$$$$
\text { as } n \longrightarrow \infty \text {. }
$$ 
Also from (4), (71), and (79)

$$
\begin{aligned}
D_{f}\left(x_{n}, T_{[n+1]} x_{n}\right) & =D_{f}\left(x_{n}, x_{n+1}\right)+D_{f}\left(x_{n+1}, T_{[n+1]} x_{n}\right)+\left\langle\nabla f\left(x_{n+1}\right)-\nabla f\left(T_{[n+1]} x_{n+1}\right), x_{n+1}-x_{n}\right\rangle \\
& =D_{f}\left(x_{n}, x_{n+1}\right)+D_{f}\left(x_{n+1}, T_{[n+1]} x_{n}\right)+\left\|\nabla f\left(T_{[n+1]} x_{n}\right)-\nabla f\left(x_{n+1}\right)\right\|\left\|x_{n+1}-x_{n}\right\| \longrightarrow 0 \quad \text { as } n \longrightarrow \infty .
\end{aligned}
$$

Using the quasi-Bregman nonexpansivity of $T_{(i)}$ for each $i$, we obtain the following finite table:

$$
\begin{aligned}
& D_{f}\left(x_{n+N}, T_{(n+N)} x_{n+N-1}\right) \longrightarrow 0 \quad \text { as } n \longrightarrow \infty \\
& D_{f}\left(T_{(n+N)} x_{n+N-1}, T_{(n+N)} T_{(n+N-1)} x_{n+N-2}\right) \longrightarrow 0 \\
& \text { as } n \longrightarrow \infty \\
& \vdots \\
& D_{f}\left(T_{(n+N)} \cdots T_{(n+2)} x_{n+1}, T_{(n+N)} \cdots T_{(n+1)} x_{n}\right) \\
& \text { as } n \longrightarrow 0 .
\end{aligned}
$$

Then, applying Lemma 10 on each line above, we obtain

$$
\begin{gathered}
x_{n+N}-T_{(n+N)} x_{n+N-1} \longrightarrow 0 \quad \text { as } n \longrightarrow \infty \\
T_{(n+N)} x_{n+N-1}-T_{(n+N)} T_{(n+N-1)} x_{n+N-2} \longrightarrow 0 \\
\text { as } n \longrightarrow \infty \\
\vdots \\
T_{(n+N)} \cdots T_{(n+2)} x_{n+1}-T_{(n+N)} \cdots T_{(n+1)} x_{n} \longrightarrow 0
\end{gathered}
$$$$
\text { as } n \longrightarrow \infty \text {, }
$$

and adding up this table, we obtain

$$
\begin{aligned}
& x_{n+N}-T_{(n+N)} T_{(n+N-1)} \cdots T_{(n+1)} x_{n} \longrightarrow 0 \\
& \quad \text { as } n \longrightarrow \infty .
\end{aligned}
$$

Using this and (68), we obtain

$$
\lim _{n \rightarrow \infty}\left\|x_{n}-T_{(n+N)} T_{(n+N-1)} \cdots T_{(n+1)} x_{n}\right\|=0 .
$$

Also from quasi-Bregman nonexpansivity of $T_{(i)}$, for each $i$, we have

$$
\begin{gathered}
D_{f}\left(T_{(n+N)} T_{(n+N-1)} \cdots T_{(n+1)} x_{n}, T_{(n+N)} T_{(n+N-1)}\right. \\
\left.\quad \cdots T_{(n+1)} y_{n}\right) \leq D_{f}\left(x_{n}, y_{n}\right) \longrightarrow 0
\end{gathered}
$$

as $n \rightarrow \infty$. Then, we have from Lemma 10 that

$$
\begin{aligned}
T_{(n+N)} & T_{(n+N-1)} \cdots T_{(n+1)} x_{n} \\
& -T_{(n+N)} T_{(n+N-1)} \cdots T_{(n+1)} y_{n} \longrightarrow 0
\end{aligned}
$$

Since

$$
\begin{aligned}
& \left\|y_{n}-T_{(n+N)} T_{(n+N-1)} \cdots T_{(n+1)} y_{n}\right\| \leq\left\|y_{n}-x_{n}\right\|+\| x_{n} \\
& \quad-T_{(n+N)} T_{(n+N-1)} \cdots+T_{(n+1)} x_{n} \| \\
& \quad+\| T_{(n+N)} T_{(n+N-1)} \cdots T_{(n+1)} x_{n} \\
& \quad-T_{(n+N)} T_{(n+N-1)} \cdots T_{(n+1)} y_{n} \|,
\end{aligned}
$$

then, from (52), (84), and (86), we obtain

$$
\lim _{n \rightarrow \infty}\left\|y_{n}-T_{(n+N)} T_{(n+N-1)} \cdots T_{(n+1)} y_{n}\right\|=0 .
$$

Following the argument from (85), (86), and (88) by replacing $y_{n}$ with $z_{n}$ and using (51), we obtain

$$
\lim _{n \rightarrow \infty}\left\|z_{n}-T_{(n+N)} T_{(n+N-1)} \cdots T_{(n+1)} z_{n}\right\|=0 .
$$

Let $\left\{x_{n}\right\}$ be a subsequence of $\left\{x_{n}\right\}$. Since $\left\{x_{n}\right\}$ is bounded and $E$ is reflexive, without loss of generality, we may assume that $x_{n_{i}} \rightarrow q$ for some $q \in F$ and since $x_{n}-z_{n} \rightarrow 0$ as $n \rightarrow \infty$, then $z_{n_{i}} \rightarrow q$. Since the pool of mappings of $T_{[n]}$ is finite, passing to a further subsequence if necessary, we may further assume that, for some $i \in\{1,2, \ldots, N\}$, from (89), we get

$$
z_{n_{i}}-T_{(i+N)} \cdots T_{(i+1)} z_{n_{i}} \longrightarrow 0 \text { as } i \longrightarrow \infty,
$$

and also

$$
\begin{aligned}
\limsup _{n \rightarrow \infty}\left\langle-\nabla f(p), z_{n}-p\right\rangle \\
\quad=\lim _{i \rightarrow \infty}\left\langle-\nabla f(p), z_{n_{i}}-p\right\rangle .
\end{aligned}
$$

Noticing that $u_{j, n}=\operatorname{Res}_{g_{j}}^{f}\left(x_{n}\right)$ for each $j=1,2, \ldots, m$, we obtain

$$
\begin{aligned}
g_{j}\left(u_{j, n}, y\right)+\left\langle y-u_{j, n}, \nabla f\left(u_{j, n}\right)-\nabla f\left(x_{n}\right)\right\rangle & \geq 0, \\
& \forall y \in C .
\end{aligned}
$$

Hence

$$
\begin{array}{r}
g_{j}\left(u_{j, n_{i}}, y\right)+\left\langle y-u_{j, n_{i}}, \nabla f\left(u_{j, n_{i}}\right)-\nabla f\left(x_{n_{i}}\right)\right\rangle \\
\forall y \in C, \\
\forall y \in C
\end{array}
$$

From (A2), we note that, for each $j=1,2, \ldots, m$,

$$
\begin{aligned}
& \left\|y-u_{j, n}\right\| \frac{\left\|\nabla f\left(u_{j, n_{i}}\right)-\nabla f\left(x_{n_{i}}\right)\right\|}{r_{n_{i}}} \\
& \geq\left\langle y-u_{j, n}, \nabla f\left(u_{j, n}\right)-\nabla f\left(x_{n}\right)\right\rangle \geq-g_{j}\left(u_{j, n_{i}}\right) \\
& \geq g_{j}\left(y, u_{j, n_{i}}\right), \quad \forall y \in C .
\end{aligned}
$$


Taking the limit as $i \rightarrow \infty$ in above inequality and from (A4) and $u_{j, n_{i}} \rightarrow q$, we have $g_{j}(y, q) \leq 0$ for each $j=1,2, \ldots, m$. For $0<t<1$ and $y \in C$, define $y_{t}=t y+(1-t) q$. Noticing that $y, q \in C$, we obtain $y_{t} \in C$, which yield that $g_{j}\left(y_{t}, q\right) \leq 0$. It follows from (A1) that

$$
\begin{aligned}
0 & =g_{j}\left(y_{t}, y_{t}\right) \leq \operatorname{tg}_{j}\left(y_{t}, y\right)+(1-t) g_{j}\left(y_{t}, q\right) \\
& \leq \operatorname{tg}_{j}\left(y_{t}, y\right) .
\end{aligned}
$$

That is, for each $j=1,2, \ldots, m$, we have $g_{j}\left(y_{t}, y\right) \geq 0$.

Let $t \downarrow 0$; from (A3), we obtain $g_{j}(q, y) \geq 0$ for any $y \in C$, for each $j=1,2, \ldots, m$. This implies that $q \in \bigcap_{j=1}^{m} \operatorname{EP}\left(g_{j}\right)$. Hence $q \in \Omega$. It follows from the definition of the Bregman projection that

$$
\begin{aligned}
& \limsup _{n \rightarrow \infty}\left\langle-\nabla f(p), z_{n}-p\right\rangle=\lim _{i \rightarrow \infty}\left\langle-\nabla f(p), z_{n_{i}}-p\right\rangle \\
& \quad \leq\langle-\nabla f(p), q-p\rangle \leq 0 .
\end{aligned}
$$

It follows from Lemma 16 and (41) that $D_{f}\left(p, x_{n}\right) \rightarrow 0$ as $n \rightarrow \infty$. Consequently, from Lemma 10, we obtain $x_{n} \rightarrow p$ as $n \rightarrow \infty$.

Case 2. Suppose $D_{f}\left(p, x_{n}\right)$ is not monotone decreasing sequences; then set $\Phi_{n}:=D_{f}\left(p, x_{n}\right)$ and let $\tau: \mathbb{N} \rightarrow \mathbb{N}$ be a mapping defined for all $n \geq N_{0}$ for some sufficiently large $N_{0}$ by

$$
\tau(n):=\max \left\{k \in \mathbb{N}: k \leq n, \Phi_{k} \leq \Phi_{k+1}\right\} .
$$

Then by Lemma $17 \tau(n)$ is a nondecreasing sequence such that $\tau(n) \rightarrow \infty$ as $n \rightarrow \infty$ and $\Phi_{\tau(n)} \leq \Phi_{\tau(n)+1}$, for $n \geq N_{0}$. Then from (40) and the fact that $\alpha_{\tau(n)} \rightarrow 0$, we obtain that

$$
\begin{aligned}
\rho_{s}^{*}\left(\left\|\nabla f\left(y_{\tau(n)}\right)-\nabla f\left(T_{[\tau(n)]}\right) y_{\tau(n)}\right\|\right) & \longrightarrow 0 \\
& \text { as } \tau(n) \longrightarrow \infty .
\end{aligned}
$$

Following the same argument as in Case 1, we obtain

$$
y_{\tau(n)}-T_{(i+N)} \cdots T_{(i+1)} y_{\tau(n)} \longrightarrow 0 \quad \text { as } \tau(n) \longrightarrow \infty,
$$

and also we obtain

$$
\limsup _{\tau(n) \rightarrow \infty}\left\langle-\nabla f(p), y_{\tau(n)}-p\right\rangle \leq 0 .
$$

Then from (41), we obtain that

$$
\begin{aligned}
0 & \leq D_{f}\left(p, x_{\tau(n)+1}\right)-D_{f}\left(p, x_{\tau(n)}\right) \\
& \leq \alpha_{\tau(n)}\left(\left\langle-\nabla f(p), y_{\tau(n)}-p\right\rangle-D_{f}\left(p, x_{\tau(n)}\right)\right) .
\end{aligned}
$$

It follows from (101) and $\Phi_{n} \leq \Phi_{\tau(n)+1}, \alpha_{\tau(n)}>0$ that

$$
D_{f}\left(p, x_{\tau(n)}\right) \leq\left\langle-\nabla f(p), y_{\tau(n)}-p\right\rangle \longrightarrow 0,
$$

as $\tau(n) \rightarrow \infty$. Thus

$$
\lim _{\tau(n) \rightarrow \infty} \Phi_{\tau(n)}=\lim _{\tau(n) \rightarrow \infty} \Phi_{\tau(n)+1}=0 .
$$

Furthermore, for $n \geq N_{0}$, if $n \neq \tau(n)$ (i.e., $\tau(n)<n$ ), because $\Phi_{j}>\Phi_{j+1}$ for $\tau(n)+1 \leq j \leq n$. it then follows that for all $n \geq N_{0}$ we have

$$
0 \leq \Phi_{n} \leq \max \left\{\Phi_{\tau(n)}, \Phi_{\tau(n)+1}\right\}=\Phi_{\tau(n)+1} .
$$

This implies that $\lim _{n \rightarrow \infty} \Phi_{n}=0$, and hence $D_{f}\left(p, x_{n}\right) \rightarrow 0$ as $n \rightarrow \infty$. Consequently, from Lemma 10, we obtain $x_{n} \rightarrow p$ as $n \rightarrow \infty$. Therefore from the above two cases, we conclude that $\left\{x_{n}\right\}$ converges strongly to $p \in \Omega$ and this completes the proof.

\section{Competing Interests}

The authors declare that there are no competing interests regarding the publication of this paper.

\section{References}

[1] E. Blum and W. Oettli, "From optimization and variational inequalities to equilibrium problems," The Mathematics Student, vol. 63, pp. 123-145, 1994.

[2] P. L. Combettes and S. A. Hirstoaga, "Equilibrium programming in Hilbert spaces," Journal of Nonlinear and Convex Analysis, vol. 6, no. 1, pp. 117-136, 2005.

[3] A. Tada and W. Takahashi, "Strong convergence theorem for an equlibrium problem and a nonexpansive mapping," in Nonlinear Analysis and Convex Analysis, A. Tada and W. Takahashi, Eds., pp. 609-617, Yokohama, Yokohama, Japan, 2007.

[4] W. Takahashi and K. Zembayashi, "Strong and weak convergence theorems for equilibrium problems and relatively nonexpansive mappings in Banach spaces," Nonlinear Analysis: Theory, Methods \& Applications, vol. 70, no. 1, pp. 45-57, 2009.

[5] S. Takahashi and W. Takahashi, "Viscosity approximation methods for equilibrium problems and fixed point problems in Hilbert spaces," Journal of Mathematical Analysis ans Applications, vol. 1331, no. 1, pp. 372-379, 2003.

[6] K. Nakajo and W. Takahashi, "Strong convergence theorems for nonexpansive mappings and nonexpansive semigroups," Journal of Mathematical Analysis and Applications, vol. 279, no. 2, pp. 372-379, 2003.

[7] L. M. Bregman, "The relaxation method for finding the common point of convex sets and its application to the solution of problems in convex programming," USSR Computational Mathematics and Mathematical Physics, vol. 7, pp. 200-217, 1967.

[8] Y. Censor and A. Lent, "An iterative row-action method for interval convex programming," Journal of Optimization Theory and Applications, vol. 34, no. 3, pp. 321-353, 1981.

[9] S. Reich and S. Sabach, "Existence and approximation of fixed points of bregman firmly nonexpansive mappings in reflexive banach spaces", in Fixed-Point Algorithms for Inverse Problems in Science and Engineering, vol. 49 of Springer Optimization and Its Applications, pp. 301-316, Springer, Berlin, Germany, 2011.

[10] S.-y. Matsushita and W. Takahashi, "Weak and strong convergence theorems for relatively nonexpansive mappings in Banach spaces," Fixed Point Theory and Applications, vol. 2004, Article ID 829453, 2004.

[11] J. Chen, Z. Wan, L. Yuan, and Y. Zheng, "Approximation of fixed points of weak bregman relatively nonexpansive mappings in banach spaces," International Journal of Mathematics and Mathematical Sciences, vol. 2011, Article ID 420192, 23 pages, 2011. 
[12] M. A. Alghamdi, N. Shahzad, and H. Zegeye, "Strong convergence theorems for Quasi-Bregman nonexpansive mappings in reflexive Banach spaces," Journal of Applied Mathematics, vol. 2014, Article ID 580686, 9 pages, 2014.

[13] C.-T. Pang, E. Naraghirad, and C.-F. Wen, "Weak convergence theorems for Bregman relatively nonexpansive mappings in BANach spaces," Journal of Applied Mathematics, vol. 2014, Article ID 573075, 9 pages, 2014.

[14] H. Zegeye and N. Shahzad, "Convergence theorems for right bregman strongly nonexpansive mappings in reflexive Banach spaces," Abstract and Applied Analysis, vol. 2014, Article ID 584395, 8 pages, 2014.

[15] H. Zegeye and N. Shahzad, "Strong convergence theorems for a common fixed point of a finite family of Bregman weak relativity nonexpansive mappings in reflexive Banach spaces," The Scientific World Journal, vol. 2014, Article ID 493450, 8 pages, 2014.

[16] W. Kumam, U. Witthayarat, P. Kumam, S. Suantai, and K. Wattanawitoon, "Convergence theorem for equilibrium problem and Bregman strongly nonexpansive mappings in Banach spaces," Optimization, vol. 65, no. 2, pp. 265-280, 2015.

[17] J. B. Hiriart-Urruty and C. Lemarchal, Convex Analysis and Minimization Algorithms II, vol. 306 of Grundlehren der Mathematischen Wissenschaften, Springer, 1993.

[18] C. Zalinescu, Convex Analysis in General Vector Spaces, World Scientific, River Edge, NJ, USA, 2002.

[19] E. Asplund and R. T. Rockafellar, "Gradients of convex functions," Transactions of the American Mathematical Society, vol. 139, pp. 443-467, 1969.

[20] J. F. Bonnans and A. Shapiro, Perturbation Analysis of Optimization Problems, Springer, New York, NY, USA, 2000.

[21] S. Reich and S. Sabach, "A strong convergence theorem for a proximal-type algorithm in reflexive Banach spaces," Journal of Nonlinear and Convex Analysis, vol. 10, no. 3, pp. 471-485, 2009.

[22] H. H. Bauschke, J. M. Borwein, and P. L. Combettes, "Essential smoothness, essential strict convexity, and Legendre functions in Banach spaces," Communications in Contemporary Mathematics, vol. 3, no. 4, pp. 615-647, 2001.

[23] E. Naraghirad and J.-C. Yao, "Bregman weak relatively nonexpansive mappings in Banach spaces," Fixed Point Theory and Applications, vol. 2013, article 141, 2013.

[24] E. Naraghirad and S. Timnak, "Strong convergence theorems for Bregman W-mappings with applications to convex feasibility problems in Banach spaces," Fixed Point Theory and Applications, vol. 2015, article 149, 2015.

[25] E. Naraghirad and J.-C. Yao, "Bregman weak relatively nonexpansive mappings in Banach spaces," Fixed Point Theory and Applications, vol. 2013, article 141, 2013.

[26] D. Butnariu and E. Resmerita, "Bregman distances, totally convex functions, and a method for solving operator equations in Banach spaces," Abstract and Applied Analysis, vol. 2006, Article ID 84919, 39 pages, 2006.

[27] F. Kohsaka and W. Takahashi, "Proximal point algorithms with Bregman functions in Banach spaces," Journal of Nonlinear and Convex Analysis, vol. 6, no. 3, pp. 505-523, 2005.

[28] H. H. Bauschke and J. M. Borwein, "Legendre functions and the method of random Bregman projections," Journal of Convex Analysis, vol. 4, no. 1, pp. 27-67, 1997.

[29] E. Resmerita, "On total convexity, Bregman projections and stability in Banach spaces," Journal of Convex Analysis, vol. 11, pp. 1-16, 2004.
[30] D. Butnariu and A. N. Iusem, Totally Convex Functions for Fixed Points Computation and Infinite Dimensional Optimization, vol. 40, Kluwer Academic, Dordrecht, The Netherlands, 2000.

[31] S. Reich and S. Sabach, "Two strong convergence theorems for a proximal method in reflexive Banach spaces," Numerical Functional Analysis and Optimization, vol. 31, no. 1, pp. 22-44, 2010.

[32] R. P. Phelps, Convex Functions, Monotone Operators and Differentiability, vol. 1364 of Lecture Notes in Mathematics, Springer, Berlin, Germany, 1993.

[33] S. Reich and S. Sabach, "Two strong convergence theorems for Bregman strongly nonexpansive operators in reflexive BANach spaces," Nonlinear Analysis: Theory, Methods \& Applications, vol. 73, no. 1, pp. 122-135, 2010.

[34] H.-K. Xu, "Another control condition in an iterative method for nonexpansive mappings," Bulletin of the Australian Mathematical Society, vol. 65, no. 1, pp. 109-113, 2002.

[35] P.-E. Maingé, "Strong convergence of projected subgradient methods for nonsmooth and nonstrictly convex minimization," Set-Valued Analysis, vol. 16, no. 7-8, pp. 899-912, 2008. 


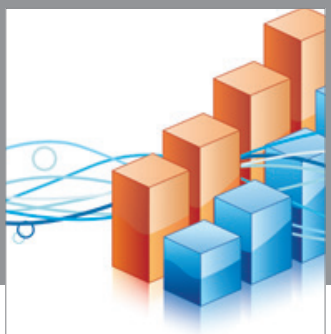

Advances in

Operations Research

vatem alat4

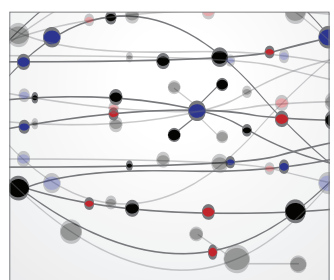

\section{The Scientific} World Journal
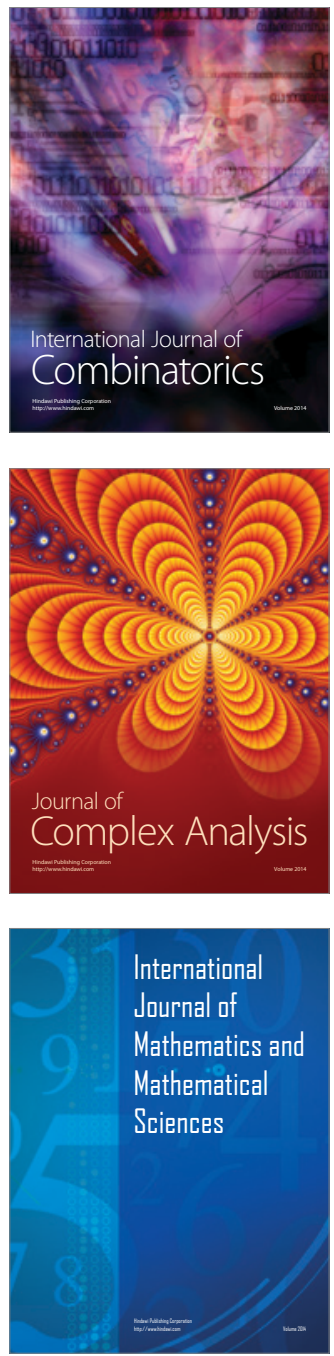
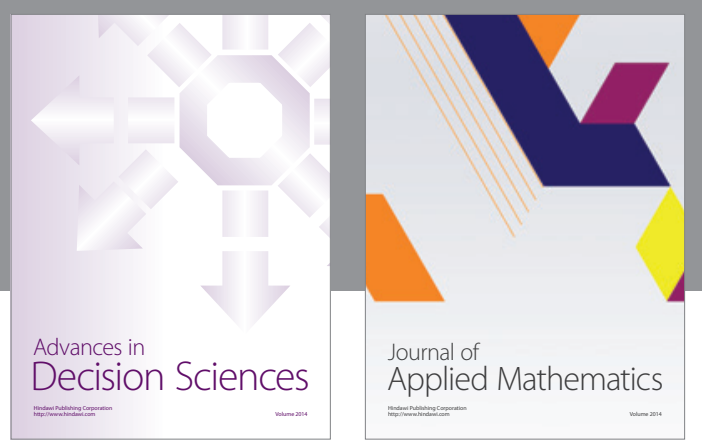

Algebra

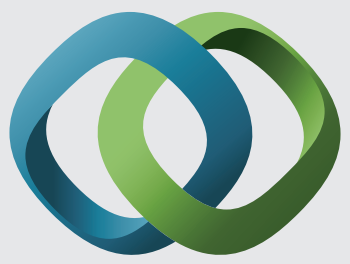

\section{Hindawi}

Submit your manuscripts at

http://www.hindawi.com
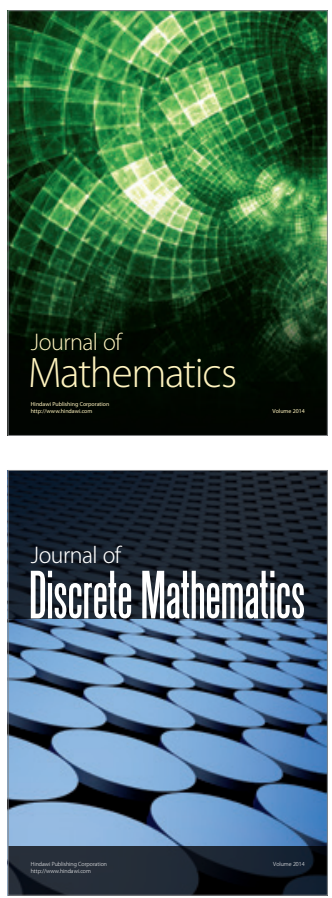

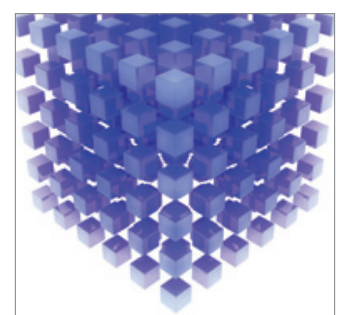

Mathematical Problems in Engineering
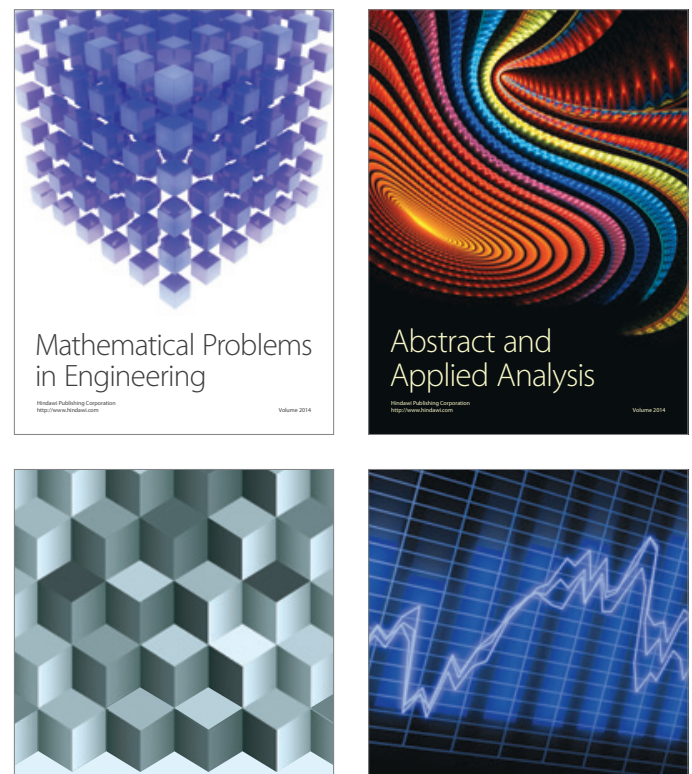

Journal of

Function Spaces

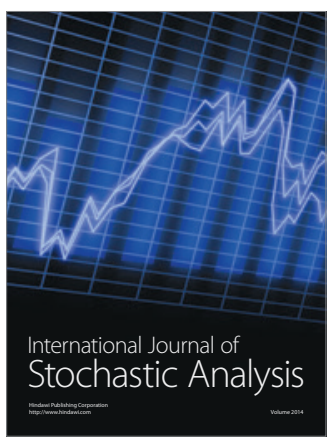

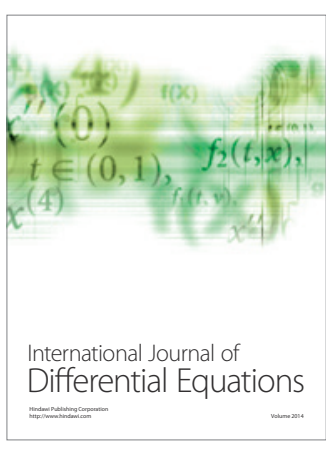
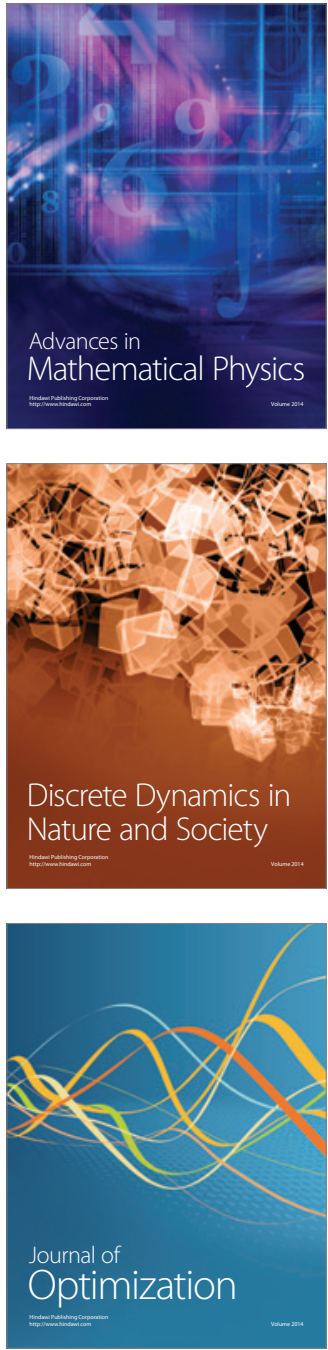